\title{
CONSTRUÇÃO COLABORATIVA DE UM PLANO DE AULA DE INGLÊS EM UM CONTEXTO DO PIBID: UM OLHAR A PARTIR DA PERSPECTIVA SOCIOCULTURAL
}

\section{COLLABORATIVE ENGLISH LESSON PLANNING IN A PIBID CONTEXT: A POINT OF VIEW FROM THE SOCIOCULTURAL PERSPECTIVE}

\author{
SILVESTRE, Viviane Pires Viana \\ vivianepvs@gmail.com \\ UEG - Universidade Estadual de Goiás
}

\begin{abstract}
RESUMO Este artigo se propõe a analisar o processo de construção colaborativa de um plano de aula de inglês. Os dados foram gerados no contexto de um subprojeto do Programa Institucional de Bolsas de Iniciação à Docência (Pibid) e analisados, prioritariamente, à luz de alguns construtos da teoria sociocultural. A análise aponta a importância da mediação e da colaboração entre os/as professores/as na coconstrução do referido plano de aula, mesmo em face de algumas tensões no processo.
\end{abstract}

PALAVRAS-CHAVE: Aula de inglês. Colaboração. Formação docente. Planejamento. Teoria sociocultural.

ABSTRACT This paper aims at analysing the collaborative process of an English lesson planning. The data were collected within the context of a project from the Teaching Iniciation Scholarship Program (Pibid) and primarily analysed in the light of some constructs of the Sociocultural Theory. The analysis points to the importance of mediation and collaboration among the teachers in the coconstruction of the lesson plan, even though some tensions occured.

KEY-WORDS: Collaboration. English lesson. Planning. Sociocultural theory. Teacher education.

\section{INTRODUÇÃO}

O trabalho docente é, por vezes, exercido de modo solitário devido a diferentes razões. Contrário a esse fato, têm surgido, especialmente na área de formação de professores/as ${ }^{1}$ de línguas, propostas de ação docente que buscam

\footnotetext{
${ }^{1}$ Opto por marcar os gêneros masculino e feminino ao longo do texto porque acredito que o uso do genérico masculino é uma forma de apagamento do gênero feminino no texto acadêmico.
} 
valorizar a aprendizagem e o ensino em colaboração (PASSONI, 2012; EL KADRI; PASSONI, 2013). Corroborando essas propostas, o objetivo deste texto é analisar o processo de construção colaborativa de um plano de aula de inglês inserido em um contexto do Programa Institucional de Bolsas de Iniciação à Docência (Pibid) ${ }^{2}$, à luz de alguns construtos da teoria sociocultural.

O planejamento colaborativo que originou os dados analisados neste texto insere-se na proposta de trabalho de um subprojeto Pibid/Inglês, desenvolvido no período de agosto de 2012 a fevereiro de 2014 em parceria com uma escola pública de tempo integral no interior do estado de Goiás que atende a uma média de 200 alunos/as. Participaram deste subprojeto dois licenciandos e quatro licenciandas do curso de Letras Português/Inglês de uma universidade pública de Goiás, uma professora do referido curso, responsável pela coordenação do subprojeto, e uma professora de inglês da escola-parceira, que atuou como supervisora e coformadora dos/as professores/as-licenciandos/as. O subprojeto se fundamentou em uma proposta de trabalho reflexivo, colaborativo e crítico. No presente texto, focalizo um dos eixos colaborativos do trabalho: o planejamento colaborativo de uma aula de inglês que ministrada pelos/as professores/as-licenciandos/as na escola-parceira, no formato de oficina de língua inglesa ${ }^{3}$.

Neste texto, constam esta parte introdutória; as considerações teóricas, na qual apresento um recorte de alguns dos desdobramentos da teoria sociocultural vygotskyana - a aprendizagem colaborativa e a relação da perspectiva sociocultural com a formação de professores/as de segunda língua/língua estrangeira ${ }^{4}$ (doravante L2/LE); o estudo, com a breve descrição de como o estudo foi desenvolvido; a análise dos dados, com foco em dois momentos distintos do planejamento colaborativo da aula (virtual e presencial); e, por fim, as últimas considerações sobre o estudo.

\footnotetext{
${ }^{2}$ Agradeço à CAPES pelo apoio financeiro que possibilitou o desenvolvimento deste estudo.

${ }^{3}$ Um relato mais detalhado sobre a proposta dessas oficinas pode ser encontrado em Silvestre et al (2013), disponível em: <http://vedipe.blessdesign.com.br/pdf/gt02/co\%20grafica/Viviane\%20Pires\%20Viana\%20Silvestre.PD F>. Acesso em: 10 jan 2014.

${ }^{4}$ Grosso modo, a principal diferença entre esses dois construtos está no contexto de aquisição da língua: língua estrangeira - não usada no contexto nacional como língua oficial; segunda língua usada no contexto nacional como língua oficial (JORDÃO, 2014). Neste artigo, uso os termos paralelamente por ter como referencial teórico autores/as que utilizam tanto um como outro termo.
} 


\section{CONSIDERAÇÕES TEÓRICAS}

A teoria sociocultural, também conhecida como teoria sócio-histórico-cultural, surge dos trabalhos seminais do psicólogo russo Lev S. Vygotsky (1896-1934) e tem como cerne elucidar o aspecto social do desenvolvimento humano. Vygotsky defende a tese de que é na interação com o outro e com o meio que o ser humano se constrói e constrói o mundo. Para Vygotsky (1998), a linguagem tem um papel essencial nesse processo, uma vez que ela serve como instrumento mediador das funções psicológicas superiores ${ }^{5}$.

Essa teoria vem sendo redesenhada ao longo dos anos por diversos estudiosos ao redor do mundo, sem que sejam perdidos os fundamentos lançados por Vygotsky. A exemplo disso, vários estudos em Linguística Aplicada tanto no exterior (LANTOLF; APPEL, 1994; DONATO, 2000; SWAIN; BROOKS; TOCALLIBELLER, 2002; JOHNSON, 2009; JOHNSON; GOLOMBEK, 2011, dentre outros) como no Brasil (FIGUEIREDO, 2001; 2006; SOUZA, 2003; LIBERALLI; MATEUS; DAMIANOVIC, 2012; VIEIRA-ABRAHÃO, 2012; PEREIRA, 2013, dentre outros) têm buscado os ensinamentos de Vygotsky e seus colaboradores para compreender diferentes aspectos do processo de ensino-aprendizagem de línguas. Dentre esses aspectos, está o papel da aprendizagem colaborativa.

\subsection{APRENDIZAGEM COLABORATIVA}

De acordo com Figueiredo (2006, p. 12):

a aprendizagem colaborativa é uma abordagem construtivista, que se refere, grosso modo, a situações educacionais em que duas ou mais pessoas aprendem ou tentam aprender algo juntas, seja por meio de interações em sala de aula ou fora dela, seja por intermédio de interações mediadas pelo computador (DILLENBOURG, 1999), cuja ênfase recai na co-construção do conhecimento dentro e a partir dessas interações. [grifos nossos]

\footnotetext{
${ }^{5}$ São exemplos de funções psicológicas superiores a memória, o pensamento, o raciocínio etc.
} 
Como destacado, a colaboração entre os pares possibilita que o conhecimento seja coconstruído na interação entre eles/as. Ainda com base em Figueiredo (2006), é possível elencar as principais características da aprendizagem colaborativa:

a) o foco está no processo;

b) os papéis dos membros do grupo não são, em geral, definidos a priori;

c) o gerenciamento das atividades é centrado no/a aluno/a;

d) alunos/as são ativos/as, professor/a é mediador/a;

e) há o compartilhamento de ideias e pontos de vista;

f) favorece o desenvolvimento de habilidades intelectuais e sociais.

Figueiredo (2006) aponta ainda que a aprendizagem colaborativa pode acontecer em ambientes virtuais, uma vez que a internet possibilita que as pessoas interajam e construam conhecimento juntas. No entanto, o autor alerta para a falta de colaboração que o ambiente virtual pode provocar, uma vez que "o fato de a interação não ser face a face pode fazer com que os interlocutores não sejam tão comprometidos e colaboradores uns com os outros" (FIGUEIREDO, 2006, p. 27).

É importante notar a ressalva de Magalhães (2002) de que a atuação colaborativa não pressupõe simetria de ideias e de participação. Pelo contrário, conflitos são esperados e podem ser também produtivos na construção do conhecimento. Como colocado por Johnson e Golombek (2011, p. 7), "é crucial à teoria sociocultural vygotskyana a noção de que os/as aprendizes precisam se envolver em algum tipo de conflito cognitivo"6.

Os entendimentos acerca da aprendizagem colaborativa, e da teoria sociocultural em geral, muito servem para compreender o processo de formação de professores/as, especialmente quando comungamos do entendimento de que "quem ensina aprende ao ensinar e quem aprende ensina ao aprender" (FREIRE, 2011, p. 25).

\subsection{A PERSPECTIVA SOCIOCULTURAL E A FORMAÇÃO DE PROFESSORES/AS} DE L2/LE

\footnotetext{
${ }^{6}$ Todas as traduções de citações em língua inglesa são de minha autoria.
} 
Segundo Johnson (2006), as bases epistemológicas da virada sociocultural que aconteceu nas ciências humanas em geral, fundamentalmente em oposição ao paradigma positivista, trouxeram impactos para a área de formação de professores/as de L2/LE no entendimento sobre a cognição docente. De acordo com a linguista aplicada, "a postura epistemológica da virada sociocultural define a aprendizagem humana como uma atividade social dinâmica, situada em contextos físicos e sociais, e distribuída entre pessoas, ferramentas e atividades" (JOHNSON, 2006, p. 237). Nesse sentido, a perspectiva sociocultural contraria o paradigma positivista que definia a aprendizagem como um processo psicológico interno, isolado na mente do/a aprendiz.

A autora alerta que a formação de professores/as de L2/LE é historicamente fundamentada no paradigma positivista, estruturada no entendimento de que a formação docente consiste no aprendizado do conteúdo a ser ensinado (língua) e de maneiras de ensinar esse conteúdo. Por outro lado,

uma perspectiva sociocultural na formação de professores[as] de línguas reconhece que a formação de professores[as] não é somente um processo de aculturação a práticas sociais de ensinar e aprender existentes, mas se constitui também em um processo dinâmico de reconstrução e transformação dessas práticas de acordo com as necessidades individuais e dos contextos de ensino particulares, o que significa que o agenciamento humano é essencial nessa perspectiva. (VIEIRA-ABRAHÃO, 2012, p. 261)

Para que a formação de professores/as de L2/LE seja coerente epistemologicamente com o modo de conceber a cognição docente da perspectiva sociocultural, Johnson (2006) considera quatro desafios a serem pensados pela área: 1) teoria/prática x práxis - superar a dicotomia teoria e prática, entendendo-os como conceitos imbricados, que informam um ao outro e sustentam o trabalho docente (práxis); 2) a legitimidade dos conhecimentos docentes - posicionar os/as professores/as como conhecedores/as e posicionar seus modos de saber a fim de atingir a práxis; 3) redesenho dos limites do desenvolvimento profissional possibilitar modelos de desenvolvimento profissional alternativos, como a aprendizagem colaborativa, que sejam relevantes para o efetivo trabalho docente; e 4) formação "localizada" de professores/as de L2/LE - "reconhecer por que professores/as de L2/LE fazem o que fazem dentro dos contextos sociais, históricos 
e culturais nos quais trabalham e a partir daí [...] coconstruir com esses/as professores/as respostas localmente apropriadas para suas necessidades" (JOHNSON, 2006, p. 246).

Nesse sentido, "de uma perspectiva sociocultural, aprender a ensinar não é a simples apropriação de habilidades ou conhecimentos de fora para dentro, mas o movimento progressivo de atividades mediadas externa e socialmente para controle interno por cada professorla" (JOHNSON; ARSHAVSKAYA, 2011, p. 199, ênfase adicionada). Nota-se, então, o papel central da mediação na formação docente, de uma perspectiva sociocultural, e da internalização - "reconstrução interna de uma operação externa" (VYGOTSKY, 1998, p.74) - para entender como se dá o processo de aprendizagem do/a professor/a.

Johnson e Golombek (2011), assim como Pereira (2013), apontam que, apesar de central à teoria sociocultural, o conceito de mediação não é explícito na proposta vygotskyana. Para Vygotsky (1998), o ser humano não age diretamente no ambiente, mas usa instrumentos para mediar essa atividade. Esses instrumentos representam artefatos culturais, conceitos e relações sociais com outras pessoas. Como indica Figueiredo (2013, p. 114), "todas as formas de mediação acontecem num contexto que as transforma em processos inerentemente socioculturais".

Pereira (2013, p. 57) destaca que "[...] a interação e a mediação são fundamentais para a formação do[a] professor[a] de LE e para seu desenvolvimento profissional". Nessa direção, Johnson e Golombek (2011) destacam a importância da mediação estratégica, em geral, fornecida pelo/a professor/a formador/a. Nas palavras das autoras, a "mediação estratégica representa assistência cognitiva, que vai de implícita a explícita, é responsiva a uma necessidade imediata e se preocupa mais com mudança cognitiva do que com desempenho comportamental" (JOHNSON; GOLOMBEK, 2011, p. 6-7, ênfase no original). Segundo as estudiosas, essa assistência deve ser moderada, uma vez que, se for exagerada (ex.: faça isso, faça aquilo) pode diminuir a agência do/a professor/a-aprendiz, ao passo que sendo limitada pode provocar frustração (ex.: Eu não consigo fazer isso).

Por fim, Johnson e Arshavskaya (2011, p. 199) concluem que, essencialmente, o objetivo final da formação de professores/as de L2/LE, de uma perspectiva sociocultural, é "promover desenvolvimento conceitual e mover os/as 
professores/as em direção a uma maior autorregulação de práticas instrucionais sustentadas teórica e pedagogicamente".

Antes de analisar como se deu o planejamento colaborativo no contexto de formação de professores/as de LE/inglês, esclareço alguns detalhes de como este estudo se realizou.

\section{O ESTUDO}

Como já mencionado, os dados deste estudo foram gerados no âmbito de um subprojeto Pibid que teve como foco a formação de professores/as de LE/inglês. Dentre as atividades desenvolvidas no subprojeto, está a proposta de planejamento colaborativo das aulas a serem ministradas, também colaborativamente, na escolaparceira. Em geral, os planejamentos aconteciam em dois momentos distintos: no ambiente virtual, por meio do e-mail compartilhado do grupo (googlegroups) e nos encontros presenciais semanais ${ }^{7}$. Todos os encontros presenciais do grupo foram gravados em áudio.

A aula em foco no planejamento analisado aqui fazia parte do projeto temático "To be or to have?: that's the question" (Ser ou ter?: eis a questão) que estava sendo desenvolvido nas oficinas de língua inglesa oferecidas pelo grupo Pibid na escolaparceira ${ }^{8}$. O objetivo geral do projeto temático era discutir a relação "ter" e "ser", provocando uma reflexão acerca do consumismo acrítico por meio do ensino de LE/inglês. Esse projeto foi desenvolvido ao longo de seis aulas, nos meses de abril, maio e início de junho de 2013 e trago para análise o planejamento da quarta aula do projeto.

\footnotetext{
${ }^{7} \mathrm{O}$ grupo se reúne às terças-feiras, no turno vespertino, na IES. Além do planejamento das aulas, esses encontros focalizam a reflexão colaborativa e crítica acerca de diferentes aspectos do ensinoaprendizagem de LE (com e sem leituras teóricas) e das atividades desenvolvidas pelo grupo.

${ }^{8} \mathrm{~A}$ escola-parceira é de tempo integral e, no período vespertino, os/as alunos/as são reagrupados/as e participam de oficinas diversas. A partir de novembro de 2012, foram organizadas duas salas para funcionamento das oficinas de língua inglesa, uma vez por semana. Cada trio de professores/aslicenciandos-as se responsabilizou por uma das salas, cuidando de três turmas (média de 15 alunos/as cada) em cada sala (turma 1: 12h35-13h20; turma 2: 13h20-14h10; turma 3: 14h10-14h45), com o apoio da professora-supervisora. Quinzenalmente, a professora-coordenadora ministra as aulas com os dois grupos de professores/as-licenciandos/as.
} 
Este estudo insere-se no paradigma qualitativo de pesquisa (DENZIN; LINCOLN, 2013). Os dados analisados advêm de dois instrumentos: mensagens de e-mails trocadas pelos/as participantes no googlegroup e transcrição da sessão de planejamento colaborativo. Neste texto, os/as participantes/as do subprojeto serão identificados pelas iniciais C, J, R, $\mathbf{P}$ (professoras-licenciandas), E, M (professoreslicenciandos), $\mathbf{S}$ (professora-supervisora) e $\mathbf{V}$ (professora-coordenadora).

Na sequência, analiso como se deu a construção colaborativa da aula de inglês, tendo como suporte teórico a perspectiva sociocultural.

\section{ANÁLISE DO PLANEJAMENTO}

Como mencionado, o planejamento colaborativo da aula de inglês aconteceu em dois momentos - virtual e presencial. Apresento, a seguir, a análise da construção colaborativa da aula nesses dois momentos separadamente.

\subsection{MOMENTO 1 - O PLANEJAMENTO COLABORATIVO NO AMBIENTE VIRTUAL (GOOGLEGROUP)}

O marco inicial do planejamento da aula 4 foi o envio, por e-mail, pela professora-coordenadora, do texto que seria trabalhado na aula ${ }^{9}$. A professoracoordenadora solicitou ao grupo que analisassem o material enviado para que dessem início à elaboração das atividades da aula. Segue a mensagem encaminhada por $\mathbf{V}$ :

"Olá, pessoal!

Acabei me esquecendo de enviar o texto ontem. Aqui está [texto enviado em arquivo anexo]. Como combinado, vejam se retiramos alguma parte ou não, que tipo de atividades podemos propor etc. (até amanhã, para começarmos a elaboração da atividade, ok?).

No aguardo.

Abçs,

V." (E-mail de V - 16/05/13, quinta-feira, 9h27)

\footnotetext{
${ }^{9}$ Adaptado de http://www.buynothingday.co.uk/.
} 
No dia seguinte, E colocou sua opinião sobre o texto "muito interessante, de fácil compreensão e muito rico", sugere a proposta de relacionar a temática do texto - consumismo - a questões ambientais e se coloca aberto a construir melhor a proposta com o apoio dos/as demais "se alguém gostou e quiser completar ou sugerir melhoras, estamos aí". Segue a mensagem enviada pelo professorlicenciando:

"Realmente é um texto muito interessante, de fácil compreensão e muito rico. Acredito que poderíamos relacionar com a duração de certos materiais, já que o texto fala muito na questão dos recursos naturais. Falar, por exemplo, o carro produzido dura, em média, 45 anos no planeta, a garrafa, tantos anos...Contudo, eles deveriam escolher os objetos antes, que eles acham que é muito consumido. Algo assim, se alguém gostou e quiser completar ou sugerir melhoras, estamos aí. Obg. Abçs, E." (E-mail de E - 17/05/13, sextafeira, 00h08)

Como já apontado, o processo colaborativo não está livre de tensões, tais como assimetria de ideias e de participação. Passados dois dias que o texto foi encaminhado ao grupo, apenas um componente havia se manifestado. A professora-coordenadora, então, interferiu e enviou outra mensagem ao grupo, desta vez, "cobrando" a colaboração dos/as demais:

"Então, pessoal, até agora apenas as contribuições do E. E nosso combinado de terça?

Até,

V." (E-mail de V - 18/05/13, sábado, 7h53)

Por vezes, a colaboração do grupo no ambiente virtual não aconteceu regularmente, ou seja, nem todos/as interagiram enviando/respondendo mensagens. No último encontro presencial do grupo (14/05/13), isso havia sido discutido e havia sido combinado que todos/as iriam colocar suas contribuições com mais assiduidade. Por isso, o lembrete da professora-coordenadora "E nosso combinado de terça?”. A partir da interferência de $\mathbf{V}$, outras professoras-licenciandas enviaram suas sugestões para a aula:

"O texto é muito bom mesmo, gostei da sua ideia, E, também poderíamos trabalhar assim: Entregarmos para os alunos certa quantidade em dinheiro 
(de brincadeirinha) e mostraríamos vários produtos a serem comprados, todos com preços. Eles escolheriam os produtos e pagariam com o dinheiro dado a eles, observaríamos se com o dinheiro na mão eles comprariam o produto e não se importariam com o preço. $O$ que acham? Abçs C." (E-mail de C - 18/05/13, sábado, 12h25)

"Oi Pessoal,

E, sua ideia é bem legal.

Em relação ao texto, como será trabalhado? Iremos entregar para os/as alunos/as e eles/as vão tentar compreender sozinhos ou com a nossa ajuda? Irão usar dicionário? Em relação ao uso do dicionário, eu acredito que não seja interessante, pois perdemos muito tempo, experiência que tivemos naquela outra atividade, mas acredito que nem há necessidade de usar dicionário.

Bom, acho que devemos trabalhar com perguntas para instigar os/as alunos/as a pensarem em torno do tema da oficina ( Ter e ser), essas questões teriam que ser mais subjetivas ...

\section{Abçs \\ J."(E-mail de J - 18/05/13, sábado, 14h26)}

Como pode ser notado no excerto acima, C sugeriu outra atividade a ser realizada e pediu a opinião dos/as demais a respeito "o que acham?". Em seguida, J trouxe sua consideração sobre a proposta de $\mathbf{E}$, mas não comentou a proposta de $\mathbf{C}$. Nessa mesma mensagem, $\mathbf{J}$ lançou questões ao grupo sobre como seria feito o trabalho com o texto "Iremos entregar para os/as alunos/as e eles/as vão tentar compreender sozinhos ou com a nossa ajuda? Irão usar dicionário?" e alertou para o uso do dicionário que, a seu ver, deveria ser evitado "perdemos muito tempo, experiência que tivemos naquela outra atividade". J, então, apresentou ao grupo a ideia de trabalhar com perguntas mais subjetivas relacionadas à temática do projeto.

No dia seguinte, a professora-coordenadora encaminhou outra mensagem ao grupo, tecendo suas considerações sobre as sugestões de atividades colocadas até o momento "as ideias do $\mathbf{E}$ e da $\boldsymbol{C}$ são muito boas, mas concordo com a $\boldsymbol{J}$ de que precisamos focar em como trabalhar questões sobre o texto" e propondo demais encaminhamentos para o planejamento da aula. Segue a mensagem.

"Olá, pessoal!

As ideias do $\boldsymbol{E}$ e da $\boldsymbol{C}$ são muito boas, mas concordo com a $\boldsymbol{J}$ de que precisamos focar em como trabalhar questões sobre o texto (ou vcs pensaram em trabalhar isso como atividade de pós-leitura?). 
Estou preocupada com a extensão do texto. Vcs acham que devemos tirar alguma parte ou daria para trabalhar ele completo mesmo?

Seria importante todos/as relermos aquele trecho das OCEM-LE que traz alguns exemplos de atividades na perspectiva do letramento crítico para elaborarmos as questões. Lembrando que precisamos elaborar algo: "pre-reading" (inclusive esclarecendo vocabulário do texto), "reading" e "post-reading".

Vamos nos falando ao longo do dia.

Abçs,

V." (E-mail de V - grifo adicionado - 19/05/13, domingo, 8h07)

No trecho em destaque do excerto acima, nota-se a mediação estratégica (JOHNSON; GOLOMBEK, 2011) da professora-coordenadora ao sugerir a releitura de um texto que havia sido estudado pelo grupo anteriormente e que trazia exemplos de atividades de leitura na perspectiva que vinha orientando as aulas propostas pelo grupo - letramento crítico ${ }^{10}$. Ao trazer essa orientação, a professoracoordenadora forneceu, de forma explícita, uma assistência cognitiva aos/às professores/as-licenciandos/as no entendimento e, consequentemente, na formulação da proposta da aula.

No mesmo dia, $\mathbf{P}$ apresentou uma proposta de roteiro para a aula, organizando as sugestões enviadas anteriormente e incluindo sua ideia para a atividade inicial. Na sequência, $\mathbf{J}$ encaminhou uma mensagem ao grupo, sugerindo que tirassem alguma parte do texto devido ao tempo que gastariam com as perguntas a serem respondidas pelos/as alunos/as. Seguem as mensagens de $\mathbf{P}$ e J.

"Primeiro, poderíamos pedir para os alunos lerem o texto e sublinharem as palavras que eles não conhecem, depois poderíamos trabalhar o vocabulário juntos com todos os alunos. Ou selecionar algumas palavras e indagá-los a respeito do entendimento.

Depois na leitura nós podemos elaborar algumas questões usando o letramento critico.

Ai por fim, utilizar ou a ideia da $\mathbf{C}$ ou a do $\boldsymbol{E}$.

\footnotetext{
${ }^{10}$ Grosso modo, o letramento crítico aborda "o processo de significação textual como um processo de construção, e não de extração; nós atribuímos sentidos a um texto ao invés de extrairmos os significados dele. Acima de tudo, o significado textual é compreendido num contexto sócio-histórico e de relações de poder, não somente como o produto ou a intenção de um autor. Além disso, a leitura é um ato de conhecer o mundo (além das palavras do texto) e uma forma de transformação social" (CERVETTI et al. , 2001 apud JORDÃO; FOGAÇA, 2007, p. 91, tradução dos autores).
} 
Abraços,
$\boldsymbol{P . " ( E - m a i l ~ d e ~ P ~ - ~ 1 9 / 0 5 / 1 3 , ~ d o m i n g o , ~ 1 7 h 0 4 ) ~}$

"Oi Pessoal,

Olha, não sei $\boldsymbol{V}$... mas acho que se formos trabalhar com as questões sobre o texto, poderíamos tirar alguma parte, devido o tempo, porque teremos que trabalhar todas as etapas que a senhora mencionou.

Abçs,

J." (E-mail de J - 19/05/13, domingo, 17h26)

Logo em seguida, $\mathbf{V}$ encaminhou outra mensagem ao grupo, perguntando se concordavam com a sugestão de $\mathbf{J}$, elogiando o encaminhamento de $\mathbf{P}$ e solicitando a elaboração de uma ou duas questões sobre o texto:

"Concordam com a J? Que parte do texto tiraríamos?

Bom encaminhamento, P. Cada um pode elaborar uma ou duas questões, então (baseadas nas ideias do letramento crítico, por isso a importância de reler aquele texto que estudamos)? Conseguem enviar até amanhã de manhã?

Abçs,

V." (E-mail de V - grifo adicionado - 19/05/13, domingo, 17h50)

No trecho em destaque do excerto acima, é possível notar, mais uma vez, a mediação estratégica (JOHNSON; GOLOMBEK, 2011) da professora-coordenadora ao ressaltar a importância de elaborarem as questões tendo como embasamento teórico a perspectiva do letramento crítico. Como apontado por Johnson e Arshavskaya (2011, p. 184),

\begin{abstract}
a responsabilidade da formação de professores/as, de uma perspectiva sociocultural, é apresentar conceitos científicos relevantes aos/às professores/as e fazê-lo de modo a mobilizar esses conceitos a uma atividade prática concreta, relacionando-os a seus conhecimentos cotidianos e atividades docentes.
\end{abstract}

Logo após a mensagem da professora-coordenadora, $\mathbf{M}$, que até o momento não havia se manifestado, enviou suas considerações ao grupo. O professorlicenciando avaliou positivamente os encaminhamentos para a aula "Penso que as ideias até agora são ótimas para a próxima oficina; acredito que a posição da $\boldsymbol{P}$ seja 
pertinente; O texto está ótimo; A ideia do E é interessante para discussão do texto", sugeriu uma atividade de pré-leitura (glossário), refutou a necessidade de retirar alguma parte do texto como sugerido anteriormente por $\mathbf{J}$ "talvez o primeiro grupo leve mais tempo, mas os demais conseguiram trabalhar tranquilamente essa atividade", e sugeriu que a atividade proposta por $\mathbf{C}$ fosse realizada em outra aula. Segue a mensagem de $\mathbf{M}$.

“Olá pessoal!

Desculpe a demora em responder.

Penso que as ideias até agora são ótimas para a próxima oficina. Inclusive estamos estudando o OCEM em estagio de LE e acredito que a posição da $\boldsymbol{P}$ seja pertinente. Além disso, podemos levar junto ao texto um glossário com as palavras chaves para facilitar a compreensão do texto e debater na pré leitura. O texto está ótimo, talvez o primeiro grupo leve mais tempo, mas os demais conseguiram trabalhar tranquilamente essaatividade.

A ideia do $\mathbf{E}$ é interessante para discussão do texto, já a ideia da $\mathbf{C}$ acho que podemos trabalhar em outra aula, assim poderíamos incluir mais coisas na atividade, como por exemplo ao comprar o 'produto' atrás viria descrito quanto tempo ele leva para se decompor... essas coisas." (E-mail de M - 19/05/13, domingo, 18h01)

A mensagem encaminhada por $\mathbf{M}$ (excerto acima) acabou servindo de fechamento para o planejamento colaborativo dessa aula no ambiente virtual. Não houve demais comentários sobre a proposta da aula, apenas o envio das questões que poderiam ser trabalhadas a partir do texto $(\mathbf{J}, \mathbf{M}, \mathbf{C}$ e $\mathbf{P}$ enviaram duas questões cada). É importante notar que uma professora-licencianda, R, e a professorasupervisora não se manifestaram durante a construção do plano de aula no ambiente virtual, o que corrobora a consideração de Souza e Sena $(2011$, p. 59) de que "muitos[as] professores[as] ainda resistem a dialogar, compartilhar, construir e difundir conhecimentos em um ambiente virtual". Nesse caso, o ambiente virtual de planejamento da aula pode ter provocado a resistência de ambas professoras em colaborarem no processo de construção do plano.

Outro fato importante de destacar é o tempo despendido pelo grupo na elaboração da aula no ambiente virtual. A primeira mensagem a respeito do plano foi 
enviada na quinta-feira e a última no domingo, ou seja, foram quatro dias de elaboração pelo grupo, em diferentes horas do dia (manhã, tarde, noite, madrugada), como podemos verificar nos excertos. Como aponta Kenski (2013, p. 59), "a tecnologia, em sua versão mais avançada, altera a relação temporal e redefine os espaços de atuação profissional. O[A] professor[a] passa a atuar em qualquer lugar, desde que esteja conectado[a] e interagindo com o trabalho". Isso indica que o tempo docente precisa ser repensado com o advento das novas tecnologias. Se, por um lado, as novas tecnologias podem otimizar o tempo gasto com preparação de aulas ou mesmo possibilitar formação à distância, por outro, pode ocupar ainda mais do tempo extraclasse (in)disponível pelo/a docente.

Segue um quadro com a síntese das sugestões de atividades para a aula encaminhadas no ambiente virtual, com seus/suas proponentes e o feedback do grupo.

Quadro 1 - Síntese das propostas de atividade construídas no ambiente virtual

\begin{tabular}{|l|c|c|}
\hline \multicolumn{1}{|c|}{ Proposta } & Proponente(s) & $\begin{array}{l}\text { Feedback } \\
\text { do grupo }\end{array}$ \\
\hline Texto "Buy nothing day" & V & Aceita \\
\hline Relação da temática do texto a questões ambientais & E & Aceita \\
\hline $\begin{array}{l}\text { Role-play - Alunos/as simulariam a compra de alguns } \\
\text { produtos }\end{array}$ & $\mathbf{C}$ & $\begin{array}{l}\text { Trabalhar } \\
\text { em outra } \\
\text { aula }\end{array}$ \\
\hline $\begin{array}{l}\text { Elaboração de questões sobre o texto na perspectiva do } \\
\text { letramento crítico }\end{array}$ & J, V e P & Aceita \\
\hline Alunos/as destacariam as palavras desconhecidas do texto & $\mathbf{P}$ & ---- \\
\hline Glossário acompanhando o texto & $\mathbf{M}$ & ---- \\
\hline Questões (8) a serem trabalhadas & J, P, C e M & --- \\
\hline
\end{tabular}

Fonte: Elaborado pela autora.

$\mathrm{Na}$ sequência, apresento e analiso a segunda parte da construção colaborativa do plano de aula.

\subsection{MOMENTO 2 - A SESSÃO DE PLANEJAMENTO COLABORATIVO}

No segundo momento do planejamento colaborativo da aula - presencial houve a participação de todos/as componentes do grupo, inclusive da professorasupervisora e da professora-licencianda que não participaram da interação no ambiente virtual. No início da sessão, a professora-coordenadora apresentou uma 
síntese do que foi construído pelo grupo por e-mail, leu dois trechos das OCEM-LE (BRASIL, 2006) que trata do trabalho com leitura na perspectiva do letramento crítico, apresentou algumas questões que ela havia elaborado e não havia enviado por e-mail para apreciação do grupo, bem como as questões que foram encaminhadas no ambiente virtual. Segue o trecho da fala de $\mathbf{V}$ no início da sessão:

"Eu fiz assim, pra otimizar um pouco o nosso tempo, eu peguei todas as contribuições de vocês por e-mail, que a gente foi mandando questões e sugestões de atividade, pra gente finalizar, né? $E$ peguei também naquelas orientações, dois trechinhos, assim, que eu acho que esclarece um pouco qual que é a proposta do letramento crítico pra atividade de leitura. [lê os trechos em voz alta] [...] Então eu acho que as questões que vocês sugeriram contemplam essa perspectiva, né, que não é pra ficar apenas no texto. E eu pensei em algumas também. Então eu vou ler as de vocês, depois eu leio as minhas, porque também não dá pra fazer tudo, a gente vai ter que selecionar, e pensar no pre e no post, né, o antes e o depois." (Depoimento de V - sessão de planejamento colaborativo - 21/05/13)

No trecho em destaque do excerto acima, nota-se a percepção de $\mathbf{V}$ de que as questões elaboradas pelo grupo contemplavam a proposta teórica que haviam estudado. Esse trecho sugere que o conceito científico - nesse caso, o estudo da proposta do letramento crítico - serviu como ferramenta psicológica para a construção e, posterior seleção, das questões que seriam trabalhadas durante a aula. Como coloca Vieira-Abrahão (2012, p. 464), "na educação de professores[as] de segunda língua, os conceitos científicos são apresentados aos[às] professores[as] para que eles[as] reestruturem e transformem seus conhecimentos cotidianos [...]" e "sejam capazes de utilizar os conceitos científicos como ferramentas psicológicas (pensar em conceitos) para a solução de problemas em contextos e atividades instrucionais" (VIEIRA-ABRAHÃO, 2012, p. 464).

Como colocado por $\mathbf{V}$ no excerto anterior "não dá pra fazer tudo, a gente vai ter que selecionar, e pensar no "pre" e no "post", né, o antes e o depois", o grupo elegeu, com base na perspectiva teórica proposta, as perguntas que melhor atendiam à proposta de trabalho com o texto e definiu o que seria, de fato, colocado no plano, tendo em vista a organização da aula nas etapas de pré-leitura, leitura e pós-leitura. Ao fazer isso, o grupo decidiu, colaborativamente, que atividades propostas no primeiro momento do planejamento (ambiente virtual) permaneceriam, 
quais seriam descartadas e quais seriam acrescentadas. Por limitações de espaço, não será possível apresentar aqui toda a construção colaborativa do plano feita presencialmente. Sendo assim, trago um recorte do processo: a decisão sobre como seria feita a atividade com as questões. Segue o quadro com o excerto.

Quadro 2 - Trecho da sessão de planejamento colaborativo (21/05/13)

\begin{tabular}{|c|c|c|}
\hline (1) & V: & $\begin{array}{l}\text { Vamos tentar determinar [...] um limite de quantas [questões], que daí eu } \\
\text { acho que fica mais fácil. Até quantas questões? }\end{array}$ \\
\hline (2) & M: & Acho que três ou quatro, não? \\
\hline (3) & C: & É, porque aí não dá tempo, né? Porque aí vai ser uma discussão, não é? \\
\hline$(4)$ & V: & $\begin{array}{l}\text { Então, aí tem que pensar nisso também, se vão ter questões pra eles } \\
\text { escreverem ou só discutir. O que vocês acham? }\end{array}$ \\
\hline (5) & S: & Acho que se for pra eles escreverem, vai levar mais tempo. \\
\hline (6) & V: & Uhum. \\
\hline$(7)$ & S: & $\begin{array}{l}\text { Porque sempre um vai enrolar, esperar um pouquinho a professora dar } \\
\text { uma luz. Então, acho que se deixar mesmo pra discussão, fazer as } \\
\text { questões, três ou quatro questões, discutir ali já encaixa uma na outra. }\end{array}$ \\
\hline (8) & M: & $\begin{array}{l}\text { A gente podia fazer também é selecionar, por exemplo, quatro questões e } \\
\text { divide em grupos, aí cada grupo tem cinco minutos pra discutir entre eles } \\
\text { pra dar uma resposta pros demais da pergunta. Porque daí daria pra eles } \\
\text { pensarem em conjunto e depois todo mundo discutir também as mesmas } \\
\text { respostas. }\end{array}$ \\
\hline & & {$[\ldots]$} \\
\hline (9) & R: & $\begin{array}{l}\text { [...] A gente podia separar em grupos, igual o } \mathbf{M} \text { falou, cada um ficava } \\
\text { com um trecho, aí eles iam sublinhar as palavras e tentar entender o que } \\
\text { está falando naquele parágrafo, aí depois sim, a gente abria pra todo } \\
\text { mundo, e cada um que ficou com o parágrafo ia falar "ah, nessa parte } \\
\text { aqui...", até fechar o texto. }\end{array}$ \\
\hline$(10)$ & V: & $\begin{array}{l}\text { Ah, entendi. Cada grupo ou dupla ficar responsável por um pedaço, só } \\
\text { pra falar do que está falando. }\end{array}$ \\
\hline (11) & R: & Uhum. Um pedacinho dele. \\
\hline
\end{tabular}

Fonte: Transcrição da gravação em áudio da sessão de planejamento colaborativo

O quadro 2 traz o momento em que os/as professores/as definem como seria feito o trabalho com as questões e ilustra como a definição dos detalhes de cada atividade foi coconstruída pelo grupo de docentes, sem a imposição de um/a ou outro/a professor/a. O quadro ilustra também que os papéis desempenhados pelos/as professores/as na construção do planejamento não foram estipulados a priori, mas surgiram no decorrer da interação entre eles/as. Houve, na sessão de planejamento, um compartilhar de ideias, sugestões e uma coconstrução do sentido da aula de inglês que estava sendo planejada, o que não implica considerar que 
esse momento foi livre de tensões e que todos/as tiveram um nível de participação homogêneo. É possível notar nos turnos 1 e 4 o papel mais marcado da professoracoordenadora como mediadora do processo colaborativo do planejamento. No entanto, todos/as professores/as tiveram a oportunidade de colocar suas contribuições na construção do plano de aula (Anexo).

$\mathrm{Na}$ análise dos dois momentos do planejamento - virtual e presencial - fica evidente a importância da interação, da mediação e da colaboração entre os/as professores/as na coconstrução do plano de aula de inglês, o que corrobora os pressupostos da teoria sociocultural mencionados anteriormente.

\section{CONSIDERAÇÕES FINAIS}

Os dois momentos do planejamento, tanto virtual como presencial, mostraram que, de fato, houve colaboração na elaboração da aula. A análise evidenciou que o planejamento colaborativo proporcionou aprendizagem aos/às envolvidos/as no processo. Retomando as características da aprendizagem colaborativa (FIGUEIREDO, 2006), é possível dizer que: o foco foi no processo de construção, apesar de o produto final ter sido o plano da aula; os papéis dos membros do grupo não foram definidos a priori; por vezes, a professora-coordenadora assumiu o papel de mediadora, e os/as demais professores/as também foram, em graus variados, ativos/as no processo; ideias e pontos de vistas foram compartilhados; e habilidades intelectuais e sociais foram desenvolvidas. Tudo isso indica que o sentido da aula de inglês em foco foi coconstruída pelos/as docentes.

A análise aponta, ainda, que houve mais participação dos membros do grupo na sessão de planejamento (presencial) do que nas interações no meio virtual. Há de se encontrar maneiras de despertar no grupo a importância da construção colaborativa também no meio virtual. Uma questão também destacada na análise foi o tempo gasto pelo grupo na elaboração do plano de aula no ambiente virtual, o que ressalta a importância de que o tempo docente seja repensado a partir do uso das novas tecnologias.

Outro ponto importante ressaltado na análise foi a importância da mediação estratégica da professora-coordenadora na construção pelos/as professores/as- 
licenciandos/as dos conceitos inerentes à proposta da aula de inglês que estava sendo planejada. Isso aponta o importante papel do outro no desenvolvimento cognitivo do ser humano, como defendido por Vygotsky. A breve análise desses dados indica que estamos no caminho para superar os desafios apresentados por Johnson (2006) na formação de professores/as de L2/LE, de uma perspectiva sociocultural.

Espero que o presente texto possa provocar reflexões e trazer contribuições não apenas para docentes da área de ensino de línguas, mas para todos/as envolvidos/as com formação de professores/as, especialmente no âmbito do Pibid.

\section{VIVIANE PIRES VIANA SILVESTRE}

Doutoranda em Letras e Linguística pela Universidade Federal de Goiás (UFG). Professora da Universidade Estadual de Goiás (UEG) - Campus Inhumas.

\section{REFERÊNCIAS}

BRASIL. Ministério da Educação. Secretaria de Educação Básica. Orientações Curriculares para o Ensino Médio - Linguagens, Códigos e suas Tecnologias. Brasília: MEC/SEB, 2006.

DENZIN, N. K.; LINCOLN, Y. S. (Ed.) The landscape of qualitative research. 4th ed. Thousand Oaks: Sage Publications, 2013.

DONATO, R. Sociocultural contributions to understanding the foreign and second language classroom. In: LANTOLF, J. P. (ed.) Sociocultural Theory and Second Language Learning. Oxford: OUP, 2000, p. 27-50.

EL KADRI, M. S.; PASSONI, T. P. Refletindo sobre avaliação em práticas de formação colaborativas: duas experiências no programa Pibid. In: MATEUS, E.; EL KADRI, M. S.; SILVA, K. A. (orgs.). Experiências de formação de professores de línguas e o Pibid: contornos, cores e matizes. Campinas: Pontes, 2013, p. 201-230.

FIGUEIREDO, F. J. Q. de. Correção com os pares: os efeitos do processo da correção dialogada na aprendizagem da escrita em língua inglesa. 2001. 340p. Tese (doutorado) - Faculdade de Letras, Universidade Federal de Minas Gerais, Belo Horizonte.

A aprendizagem colaborativa de línguas: algumas considerações conceituais e terminológicas. In: FIGUEIREIDO, F. J. Q. de. (org.). A aprendizagem colaborativa de línguas. Goiânia: Ed. da UFG, 2006, p. 11-45. 
Conversas com Francisco J. Q. de Figueiredo. In: SILVA, K. A. da.; $\overline{\mathrm{ARAGÃO}}$, R. C. (orgs.). Conversas com formadores de professores de línguas: avanços e desafios. Campinas: Pontes Editores, 2013, p. 113-122.

FREIRE, P. Pedagogia da autonomia: saberes necessários à prática educativa. São Paulo: Paz e Terra, 2011.

JOHNSON, K. E. The sociocultural turn and its challenges for second language teacher education. TESOL Quarterly, n. 40, v.1, p. 235-257, 2006.

Second language teacher education: a sociocultural perspective. New York: Routledge, 2009.

JOHNSON, K. E.; ARSHAVSKAYA, E. Strategic mediation in learning to teach: reconceptualizing the microteaching simulation in an MA TESL Methodology Course. In: JOHNSON, K. E.; GOLOMBEK, P. R. (eds.). Research on second language teacher education: a sociocultural perspective in professional development. New York: Routledge, 2011. p. 168-186.

JOHNSON, K. E.; GOLOMBEK, P. R. Research on second language teacher education: a sociocultural perspective in professional development. New York: Routledge, 2011.

JORDÃO, C. M.; FOGAÇA, F. C. Ensino de inglês, letramento crítico e cidadania: um triângulo amoroso bem-sucedido. Línguas \& Letras, v. 8, n. 14, p. 79-105, $1^{\circ}$ sem. 2007.

JORDÃO, C. M. ILA - ILF - ILE - ILG: Quem dá conta? Revista Brasileira de Linguística Aplicada. v. 14, n. 1, p. 13-40, jan./mar. 2014.

KENSKI, V. M. Tecnologias e tempo docente. Campinas: Papirus, 2013.

LANTOLF, J. P.; APPEL, G. Theoretical framework: na introduction to Vygotskian approaches to second language research. In: LANTOLF, J. P.; APPEL, G. (ed.) Vygotskian Approaches to Second Language Research. New Jersey: Ablex Publishing Corporation, 1994, p. 1-32.

LIBERALLI, F. C.; MATEUS, E.; DAMIANOVIC, M. C. (orgs.) A teoria da atividade sócio-histórico-cultural e a escola: recriando realidades sociais. Campinas: Pontes, 2012.

MAGALHÃES, M. C. C. O professor de línguas como pesquisador de sua ação: a pesquisa colaborativa. In: GIMENEZ, T. (org.). Trajetórias na formação de professores de línguas. Londrina: UEL, 2002, p. 39-58.

PASSONI, T. P. Constituição de um terceiro espaço em um programa de formação de professores de inglês: contribuições do planejamento crítico-colaborativo de 
aulas. In: LIBERALLI, F. C.; MATEUS, E.; DAMIANOVIC, M. C. (orgs.) A teoria da atividade sócio-histórico-cultural e a escola: recriando realidades sociais. Campinas: Pontes, 2012, p. 175- 197.

PEREIRA, P. G. Docência em língua inglesa nas perspectivas crítica e sóciohistórico-cultural: as experiências de dois alunos-professores em formação inicial na disciplina em estágio supervisionado. 2013. Tese (doutorado) - Faculdade de Letras, Universidade Federal de Goiás, Goiânia.

SILVESTRE, V. P. S. et al. A perspectiva crítica no ensino de língua estrangeira/inglês na escola: relato de uma experiência inicial com o Pibid (22361596). In: V Encontro Estadual de Didática e Práticas de Ensino - Edipe, 5, 2013, Goiânia, GO. Anais (on-line). Goiânia, Universidade Federal de Goiás (UFG), 2013. p. 1-13. Disponível em:

<http://vedipe.blessdesign.com.br/pdf/gt02/co\%20grafica/Viviane\%20Pires\%20Viana \%20Silvestre.PDF>. Acesso em: 10 jan 2014.

SOUZA, R. A. Telecolaboração e divergência em uma experiência de aprendizagem de português e inglês como línguas estrangeiras. Revista Brasileira de Linguística Aplicada, v. 3, n. 2, p. 73-96, 2003.

SOUZA, E. P.; SENA, C. P. P. Formação de Professores em Ambiente Virtual de Aprendizagem: a mineração de dados contribuindo para a análise das interações. Informática na educação: teoria \& prática. Porto Alegre, v. 14, n. 2, p. 47-61, jul./dez. 2011.

SWAIN; M.; BROOKS; L.; TOCALLI-BELLER, A. Peer-peer dialogue as a means of second language learning. Annual Review of Applied Linguistics, v. 22, p. 171-185, 2002.

VIEIRA-ABRAHÃO, M. H. A Formação do Professor de Línguas de uma Perspectiva Sociocultural. SIGNUM: Estud. Ling., Londrina, n. 15/2, p. 457-480, dez. 2012.

VYGOTSKY, L. S. Formação social da mente. São Paulo: Martins Fontes, 1998. 


\section{ANEXO}

Collaborative lesson plan 4

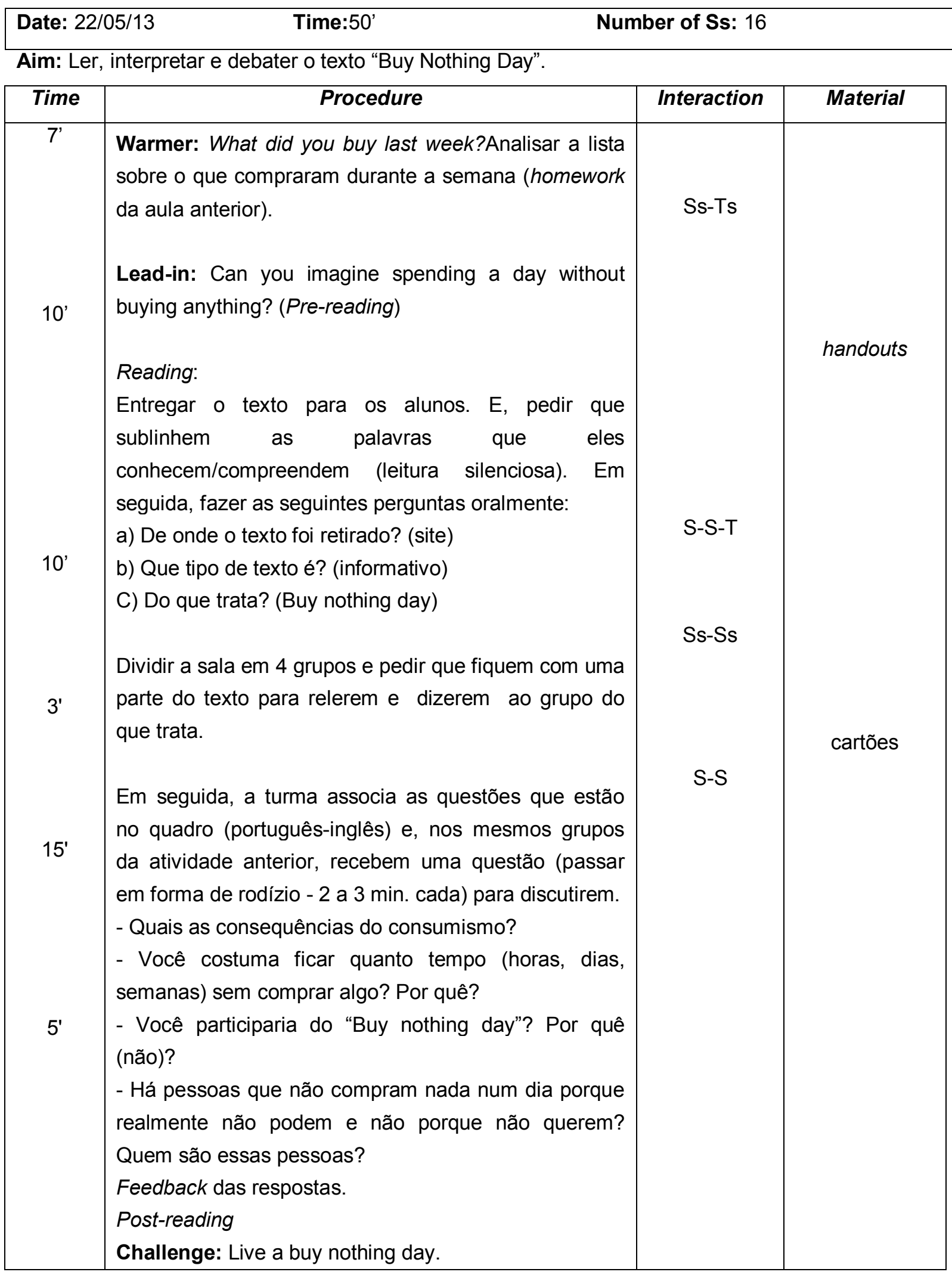

